\title{
Contextualizing Mobile IT
}

\author{
Jörn Messeter \\ Space \& Virtuality studio, \\ Interactive institute \\ Malmö, Sweden \\ Jorn.Messeter@k3.mah.se
}

\author{
Eva Brandt \\ Space \& Virtuality studio, \\ Interactive institute \\ Malmö, Sweden \\ Eva.Brandt@k3.mah.se
}

\author{
Joachim Halse \\ Space \& Virtuality studio, \\ Interactive institute \\ Malmö, Sweden \\ Joachim.Halse@tii.se
}

\author{
Martin Johansson \\ Space \& Virtuality studio, \\ Interactive institute \\ Malmö, Sweden \\ Martin.Johansson@tii.se
}

\begin{abstract}
Information and communication technologies are moving into the era of ubiquitous computing, with increased density of technology and increased mobility and continuity in use. From a design perspective, addressing the accommodation and coordination of multiple devices and services in situated use across different contexts is becoming increasingly important. In the COMIT project, ethnographic fieldwork has been combined with participatory design engaging users, designers and researchers in order to explore mobile IT use as well as the design of mobile IT concepts. Four seclected scenarios from the project are presented and discussed regarding implications for the design of mobile IT devices, with particular focus on (1) coping with multiple social contexts, and (2) the configuration and connectivity of mobile devices.
\end{abstract}

Categories \& Subject Descriptors: H.5.2 [Information Interfaces and Presentation]: User Interfaces - usercentered design.

General Terms: Design, Human Factors.

Keywords: Mobile technology; participatory design; ethnography; use qualities; contextual factors.

\section{INTRODUCTION}

Information and communication technologies are moving into what Weiser [20] termed ubiquitous computing, with ubiquitous access to digital information through a wide range of mobile and embedded technologies connected through wireless global networks. Research in ubiquitous computing, and the related fields of tangible interaction [11] and augmented reality [21], have arguably redirected the agenda for designing mobile IT. The main issue addressed has been the accommodation of a higher density of technology by letting interaction with information and communication devices blend in with our everyday ways of 'being in the world' (e.g. research into issues like context awareness; speech, gesture and handwriting recognition; etc). From a user perspective, there are a number of consequences resulting from this development. The number of personal devices typically carried by

Permission to make digital or hard copies of all or part of this work for personal or classroom use is granted without fee provided that copies are not made or distributed for profit or commercial advantage and that copies bear this notice and the full citation on the first page. To copy otherwise, or republish, to post on servers or to redistribute to lists, requires prior specific permission and/or a fee.

DIS2004, August 1-4, 2004, Cambridge, Massachusetts, USA

Copyright 2004 ACM 1-58113-787-7/04/0008...\$5.00. the mobile user is increasing. Using multiple devices in a dynamic landscape of pervasive technologies introduces another layer of complexity for the mobile IT user. Also, the role of each device is becoming more dynamic as the connection to other devices may increase the number of available functions. A simple example is that a cell phone on the market today supporting Bluetooth ${ }^{\mathrm{TM}}$ can be configured as a remote control for a presentation running on a laptop computer. Finally, the technological development not only increases technology density and connectivity but, perhaps more importantly, it increases mobility and continuity in IT use. An important consequence of being continuously connected is that as we move through different social contexts in our everyday life, we find ourselves omni-present in multiple social contexts, each with its own activities and roles. We used to have a clearer connection between places and activities which kept work and private life apart, but the wireless technologies are shifting the social meaning of places and locations [3]. For instance, business travelers may seamlessly shift between work activities, their personal lives, and the logistics of being on the move - an interplay between planned and improvised action referred to by Sherry \& Salvador [18] as the 'jazz of going mobile' [ibid, p.112]. However, the designer is coming under increasing pressure to accommodate the coordination of multiple devices and services across different contexts. In particular, the dynamics in use makes it increasingly difficult for the designer to predict use situations, calling for better approaches to build an understanding of problems and possibilities in the early phases of the design process. In the project COMIT - Contextualization of Mobile IT - we have aimed to develop an approach where rapid ethnography and participatory design are combined to explore issues in mobility across different contexts in order to better inform the design process. This study and approach run over a five-month period has brought together designers, researchers and prospective users to develop ideas and concepts for mobile IT based on ethnographic field studies. This paper describes the process and outcomes of this collaborative exploration and discusses four selected examples indicating the potentials in our approach to inform mobile IT design.

\section{WRESTLING WITH THE CLICHÉ 'NOMADIC USER'}

Mobile technologies have introduced the notion of the 'nomadic user'. In everyday marketing the dominating cliché of the nomadic user seems to be the business person aged 30 to 40 and always on-line. They handle the demands of work and family life simultaneously and with equal efficiency. Even if 
connectivity and location-based services receive a lot of attention in the mobile technology industry, the dominating rhetoric still revolves around providing the functionality of the conventional office environment 'anytime and anywhere', regardless of contextual factors. The nomadic user handles multiple contexts, not by adapting to the particularities of each use situation, but simply by disregarding contextual factors. The business meeting can take place on any forms of transport as well as in the office by providing wireless access to digitally mediated information regardless of time and place. The user becomes nomadic not by adapting to context but rather by detaching from it - 'the context-free user'. In contrast, later research in mobile technology use has underlined the social shaping of technologies [19] and the unexpected ubiquitous use of SMS being an often referred example. The use of SMS by young people tends to be driven by normative motives rather than the system being 'easy, quick and cheap' (ibid). Earlier research has pointed out how mobile technology may blur the border between different contexts. In particular, the border between work and leisure has been addressed and results are inconclusive. According to Gant and Kiesler [8], work related issues are expected to invade private life, whereas Harper [10] claims that mobile technology, allows private life to invade the work domain as well as public spaces. As a starting point we acknowledge that mobile users typically participate in many different social contexts, some being part of private life and others being work related. There have been attempts to formalize the kinds of social contexts we participate in. Rowson [16] suggests a two-dimensional scenario space with a matrix of relationship (Community, Formal Team, Casual Team, Individual) vs. role (School, Recreation, Family, Work, Spiritual). However, such general formalizations fail to account for qualitative differences between the many social contexts we encounter, as well as not being able to recognize the qualitative differences in the many forms of participation that may be applicable for each context. Furthermore, mobile technology transforms our conception of space beyond the mere geographical aspect of being mobile. An example would be travelling by train. Listening to a person talking on a mobile phone it would be questionable if we are part of the technology mediated 'social space' established between the caller and the person called. In their study of business travellers Sherry and Salvador [18] acknowledge the need for handling omnipresence in multiple contexts and go on to claim that mobility in itself often requires users to switch between planned and improvised action. They identify three experience types where the need for handling the interplay between plans and improvisation is particularly prominent: (1) handling the logistics of being on the move, e.g. finding alternatives to a cancelled flight; (2) dealing with work, e.g. compensating for documents or other resources not available in a mobile situation; and (3) managing personal affairs, e.g. staying in touch with family or managing household logistics. In order to cope with the challenges of ever changing contexts, social as well as technological, a dominating theme in mobile computing research has been context awareness. In context aware systems, contextual information is used to adapt to changing conditions and provide functionality in order to respond to the user's specific needs in a given situation. For example, in the 'nomadic radio system' [17] alert strategies for incoming messages are dynamically adapted to the 'interrupt ability' of the user. Location has been identified as the key contextual factor for mobile systems [7]. However, an ideal context aware system would account for five contextual factors, according to Abowd \& Mynatt [1]: who is the user and who else is present in the immediate environment; what is the user doing; where is the user located; when - at what time is this happening; and why - what is the emotional state of the user. In this perspective, the vision of the nomadic user is based on continuous adaptation of technology to the specific needs of the current situation. The user becomes nomadic by the system's capability of adapting to constantly changing contexts. However, it is difficult to make reliable predictions of these changes in user needs, based on contextual information picked up from the environment. The 'nomadic radio system' [17] uses real-time analysis of the auditory scene to generate context information. Continous speech from several people is interpreted as an indication of a conversational situation. This strategy presumably could break down in a noisy environment. If we consider how humans interrupt an on-going conversation with an important message, they would rely on a complex system of cues deeply rooted in social behaviour to do this.

The concepts for mobile IT developed in the COMIT project have deliberately been geared towards seeking alternatives to the strategies of context aware computing. The aim being to keep the user in control in order to make technology understandable rather than letting it disappear behind an automated technological response. In an earlier project we have addressed these issues in a specific work context [14]. A handheld device was designed to support process control operators at a waste water treatment plant. This device allowed for multiple readings from various locations in the plant to be temporarily monitored in order to analyze potential or existing problem situations. Our aim in the COMIT project has been to pursue user control in mobile IT use. Of particular importance is the investigation into multiple contexts, relating to both work and private life.

\section{THE COMIT PROJECT}

As mentioned above, the project combines ethnographic fieldwork with participatory design techniques as an approach to exploring various avenues in mobile technology. The primary aim was to develop a deeper understanding of the contextual issues in mobile computing that we are increasingly encountering. Researchers, designers and users collaborated to investigate these avenues in mobile computing through developing interactive concepts for mobile IT. The project was preceded by a pilot workshop with the participation of Sony Ericsson Mobile Communications AB and Telia Re- 
search $\mathrm{AB}$. The designers participating in the main part of the project came from three industrial partners:

- Sony Ericsson Mobile Communications AB;

- Anoto AB (digital pen technology); and

- Decuma AB (handwriting recognition software).

Concise studies of three users and the technology they employ have been conducted. Existing personal devices were not prescriptive to the design process. By inviting the users into a collaborative design process a richer view of their relevant needs was attained due to scrutinizing existing mobile products as well as future possibilities.

Table 1. The COMIT process.

\begin{tabular}{|l|l|l|l|}
\hline Iteration & User context & $\begin{array}{l}\text { Collaborative } \\
\text { design }\end{array}$ & $\begin{array}{l}\text { Validation / } \\
\text { refinement }\end{array}$ \\
\hline 1:st & Field work & Pilot workshop & Scenarios \\
\hline 2:nd & $\begin{array}{l}\text { Suppl. fieldwork } \\
\text { Cultural probes }\end{array}$ & Workshop \#1 & $\begin{array}{l}\text { Scenarios, } \\
\text { concepts }\end{array}$ \\
\hline 3:rd & $\begin{array}{l}\text { Ethnographic } \\
\text { enactment }\end{array}$ & Workshop \#2 & $\begin{array}{l}\text { Elaboratied } \\
\text { concepts }\end{array}$ \\
\hline
\end{tabular}

In the project concepts were developed addressing the invidual needs of the three participating users as well as keeping a broader perspective of mobile IT use in mind. We deliberately worked simultaneously with form, function and interaction in parallel from the very beginning of the project. The design process was event driven [4] including three iterations (see table 1) where each iteration involved activities in the user's own contexts (left column), collaborative design events involving designers, users and researchers (middle column), and finally validation and refinement after each workshop (right column).

\section{FIRST ITERATION}

\section{Fieldwork - 'On the way home'}

The three users selected were from our network of contacts from previous projects. We were not specifically looking for early adopters of mobile technology but people with a competency in cell phone use, including the use of SMS. The theme for the initial field study was 'On the way home', placing the ordinary 'man in the street' on the border between work and leisure. Helle, Ronny and Rickard (see figure 1) were followed, observed and interviewed during their last working hours and through evening. The aim was to capture a material providing a rich description of their everyday doings with a particular focus on how they moved between different social contexts. Six field trips were conducted, each covering three to six hours, and recorded on video camera. The video material was edited into short video clips to be used in the following pilot workshop.

\section{Pilot Workshop - Developing Scenarios}

The purpose of the pilot workshop was to explore the possibilities of collaborative inquiry into the dynamic needs of mobile users. Researchers, designers and users were brought together to build future scenarios for Helle, Rickard and
Ronny from the ethnographic material collected, with a focus on the needs of mobile users. The pilot workshop also served as an introduction to our way of working with field material and user involvement (for more details, see [5] and [12]). As a result of the pilot workshop the partners reached an agreement for future engagement.

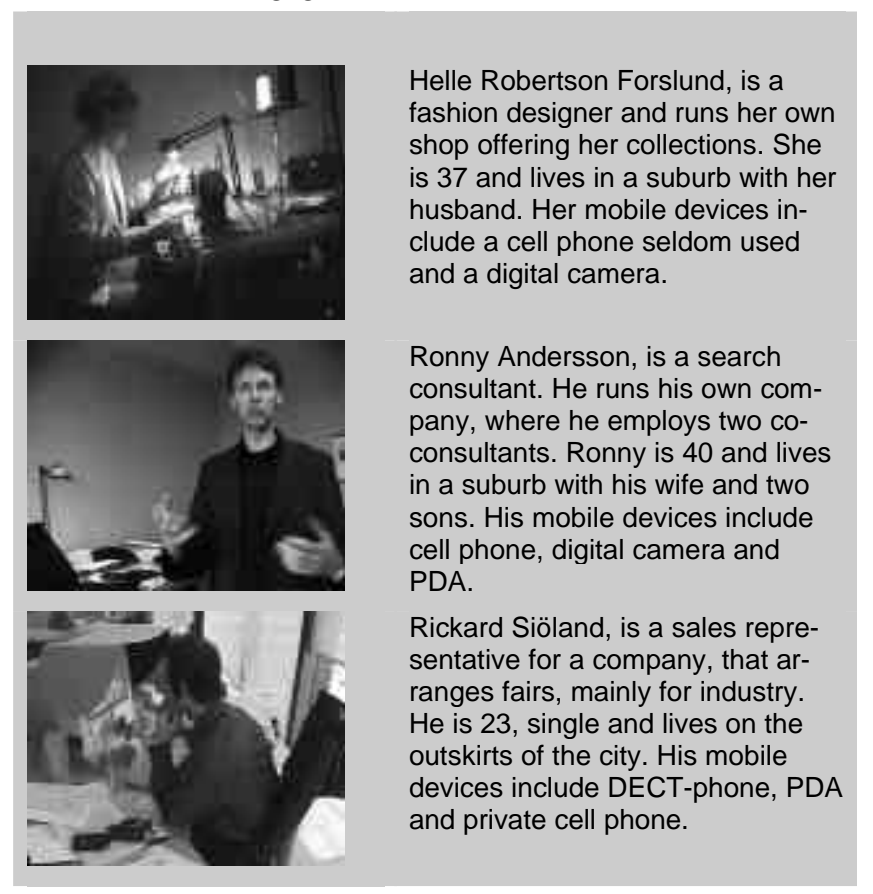

Figure 1. Short presentation of the potential users.

\section{SECOND ITERATION}

\section{Supplementary Fieldwork}

After the pilot workshop, supplementary field visits with two of the users, Rickard and Helle, took place. Also, inspired by Gaver et al [9], the field visits were supplemented by cultural probing kits. These were given to all three users in order to add more depth to user descriptions as well as opening new perspectives. The cultural probing kit consisted of a disposable camera, writing utensils and four tasks where the users traced their whereabouts during one week. For instance they took photographs of high- and low-tech products that were important to them. They also took photographs of places inside and outside their home where they liked to be. The results of these probing tasks added more nuances to user descriptions, communicating aspects of the user's dreams, hopes, fears, aspirations, and frustrations. This kind of field study differs from traditional ethnography. However, the approach used was efficient in gaining an intimate knowledge of the users and their life worlds.

\section{Workshop 1}

The aim of the first workshop was to produce future scenarios for the three users, based on the field data collected, demonstrating how mobile IT could support the users in everyday activities across different social contexts and situations. Workshop 1 had three sessions: getting to know the users by 
exploring the field material (text, images and video from the ethnographic fieldwork and probing kits); disassembling products from the industrial partners into a list of modular functions that could then be rearranged to reflect new configuration needs; and developing future scenarios based on the first two sessions. The work was carried out in three groups, each working with material from one of the users. However, the users did not work on their own material/scenarios. A starting point for developing mobile IT concepts in the first workshop was that they should utilize technology available today or in the next six months. Each of the industry partners was asked to provide a list of functions available in current or coming products that they wanted to bring into the design process, thus extracting functions typically supported with today's technology. A total of twenty functions were provided. Examples include: write and store formatted text; draw/sketch; read barcode; display video; play music; control other device. For each concept a physical shape was chosen among twelve block foam models with generic shapes. During the first workshop two to four scenarios were produced for each user giving a total of ten scenarios with associated design concepts.

\section{Validating/refining Scenarios And Concepts}

After workshop 1 the concepts and scenarios generated, needed to be grounded in the world of the intended users for validation. First, researchers elaborated on concepts from the workshop in more detail and discussed them with the users in separate meetings. Some concepts required further elaboration together with the users; other concepts were considered inadequate by the users and subsequently dropped. Table 2 summarizes the design concepts after verification with the users. Since the list of functions presented at the workshop came from current or coming products, some of them matched off-the-shelf products currently on the market, e.g. the 'image device'. However, in the process we avoided talking about the 'image device' as a digital camera to encourage new ideas rather than getting caught in the framework of existing standard mobile products.

\section{THIRD ITERATION}

\section{Ethnographic Enactment}

The next step was to create enacted scenarios together with the users in their everyday contexts. We have earlier worked with ethnographic video as a design material in which we capture prototypical work situations which prompt new design ideas $[2,5,6,12]$. Initially, the users were asked to give each concept a shape using foam material and tools supplied by the researchers. Secondly, an everyday situation was selected together with the user and a scenario was developed where the developed concepts could apply. A video recording of the scenario was conducted with the user in an informal and improvised way. The users were 'acting' as themselves using the foam shapes as props in their own everyday environments. The video scenarios, comprising between three and eight minutes each, were prepared as design material for workshop 2.
Table 2. Preliminary concepts developed.

\begin{tabular}{|c|c|}
\hline Concept & Description \\
\hline \multicolumn{2}{|l|}{ User: Helle } \\
\hline $\begin{array}{l}\text { Image } \\
\text { device }\end{array}$ & $\begin{array}{l}\text { Used for taking high-resolution pictures. Pictures can be } \\
\text { remotely stored and printed. }\end{array}$ \\
\hline $\begin{array}{l}\text { Image } \\
\text { editing } \\
\text { tablet }\end{array}$ & $\begin{array}{l}\text { Used for annotating images by writing comments or } \\
\text { drawing directly in the picture using a stylus on the } \\
\text { tablet. Images can be sent/received using personal or } \\
\text { local area network. }\end{array}$ \\
\hline $\begin{array}{l}\text { Image } \\
\text { editing } \\
\text { tablet, } \\
\text { foldable }\end{array}$ & Same as above but foldable for portability. \\
\hline $\begin{array}{l}\text { Portable } \\
\text { printer }\end{array}$ & $\begin{array}{l}\text { Used for printing documents while on the move. Sup- } \\
\text { ports wireless access from other personal devices. }\end{array}$ \\
\hline \multicolumn{2}{|c|}{ User: Rickard } \\
\hline Reminder & $\begin{array}{l}\text { Small device worn as a wrist watch and operated } \\
\text { through voice control or with a mini stylus. Its main } \\
\text { function is to remind the user of urgent activities } \\
\text { through various feedback mechanisms: sound, smell, } \\
\text { vibration, temperature, and colour. }\end{array}$ \\
\hline $\begin{array}{l}\text { Social } \\
\text { network } \\
\text { communi- } \\
\text { cator }\end{array}$ & $\begin{array}{l}\text { Maintains existing social network and provides access } \\
\text { to friends' friends. Separate from work related tasks and } \\
\text { communications. It supports conversations, awareness } \\
\text { of friends, etc. Communication is immediate: messages } \\
\text { are not stored. The user can communicate his emotional } \\
\text { state, level of accessibility, and interest in physical } \\
\text { meeting to the whole network or selected people. }\end{array}$ \\
\hline Soft key & $\begin{array}{l}\text { The soft key is used for getting temporary access to a } \\
\text { shared resource without having to physically hand over } \\
\text { a key or a card. For example, if lending your car to a } \\
\text { friend you can set up her soft key for access to your car } \\
\text { temporarily, e.g. for the next three hours. This is done } \\
\text { remotely over a wireless network and therefore makes } \\
\text { sharing of resources easier. }\end{array}$ \\
\hline \multicolumn{2}{|l|}{ User: Ronny } \\
\hline Connector & $\begin{array}{l}\text { Provides mobile connection to a shared workspace. Its } \\
\text { limited interface makes it a good companion to a dis- } \\
\text { play device. }\end{array}$ \\
\hline $\begin{array}{l}\text { Day care } \\
\text { communica- } \\
\text { tion device }\end{array}$ & $\begin{array}{l}\text { Provides direct text or voice communication with par- } \\
\text { ents of all children at a day care centre. }\end{array}$ \\
\hline $\begin{array}{l}\text { Family } \\
\text { messaging } \\
\text { device }\end{array}$ & $\begin{array}{l}\text { Handheld device offering asynchronous messaging for } \\
\text { communicating and synchronizing in daily activities. It } \\
\text { allows users to read and write messages anytime, any- } \\
\text { where using text or voice. }\end{array}$ \\
\hline $\begin{array}{l}\text { Video de- } \\
\text { vice }\end{array}$ & $\begin{array}{l}\text { Used for video recording and simple editing 'on-the- } \\
\text { fly'. }\end{array}$ \\
\hline
\end{tabular}

Workshop 2

This workshop was divided into two parts: exploring use experiences and from use experiences to form and function. The work was carried out in three groups facilitated by researchers with participants from industry, this time working together with the user described in the working material for the group. In the first part, exploring use experiences, the groups were asked to walk through the enacted scenarios and together with the user identify the use experiences regarded as most important in each scenario. In the second part, from use experiences to form and function, the groups worked with the mobile technology concepts introduced in the scenarios. Starting with the identified use experiences, the goal was to open new de- 
sign ideas and to elaborate on the concepts, regarding form as well as function. Moving from concepts grounded in enacted scenarios to identifying expected use experiences was an attempt to avoid closing the space of available design solutions prematurely by temporarily elevating the design focus to a higher level of abstraction.

\section{CONTEXTUALIZING MOBILE IT - FOUR EXAMPLES}

The fieldwork conducted in the project provided rich descriptions of our prospective mobile IT users, how they handle different contexts and how mobile technology may support them. Furthermore, the collaborative design process helped us in refining this understanding which was further expressed in the concepts and ideas developed in the collaboration. The following sections present four examples illustrating aspects of mobile IT use that we find relevant for designing mobile technology.

\section{Multiple Devices - Multiple Identities}

The first example is taken from our fieldwork. Our field data revealed several cases where users were already fluent in handling multiple devices and to some extent they also shifted between different social roles. However, our interpretation revealed that these smooth transitions are more as a result of their abilities as human beings and professionals in adapting to the situation rather than from good design. The situation illustrated in Figure 2 with Rickard (the sales agent) is extracted from a few minutes of his daily work. This situation was identified already in the pilot workshop as illustrating the switch between different social contexts. Rickard has four devices at his desk: a PC, a PDA, a cellular phone and a private cellular phone. In handling the situation Rickard moves swiftly back and forth between three roles: sales agent, colleague and friend. With the same agility he switches between using his four devices. In the video Rickard's role switching is evident in his voice, his manner of speaking and his posture. When dialling a customer he uses the moment before they answer to put a question to a colleague on a company policy matter (3a-b). As the customer answers he interrupts his conversation with his colleague who stays, apparently expecting them to finish the conversation in a short while. While he is waiting for his call to be put through from the switchboard to the right person, he finishes the conversation with his colleague (3c-d). In this sequence Rickard is switching between his business-like manner in talking to the customer and his more informal style of conversation with his colleague.

The same role switching is apparent in the second half of the sequence where Rickard, during working time makes a call to a friend, switching to a mode of talking and gesturing that displays Rickard as a private person (3e-j). When a customer calls during his conversation he briskly interrupts his friend and hangs up to switch to his sales agent role and takes the call. Finishing the conversation would most probably be handled differently, had he been interrupted by another private call or the approach from a colleague wanting to talk to him. Finally, Rickard's fluency in switching between using

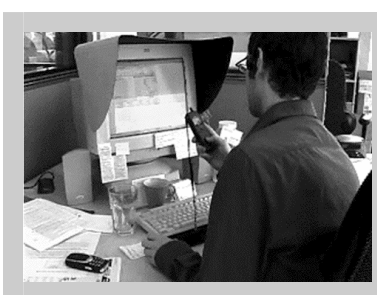

a) (Sales agent) Rickard calls a customer.

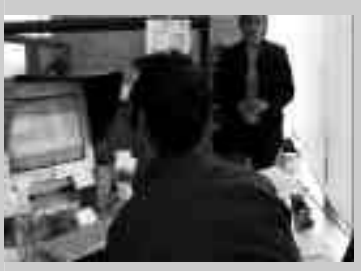

c) (Sales agent) The customer answers and Rickard interrupts his conversation with his colleague, but she stays.

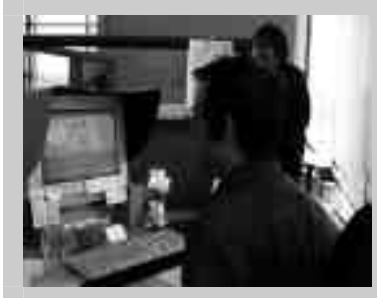

e) (Sales agent) Rickard is put through and completes his phone call.

g) (Sales agent) Rickard's conversation with his friend is interrupted by a customer call.

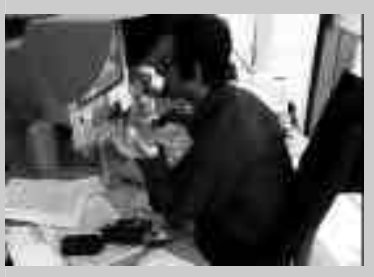

i) (Friend) Rickard calls back to his friend and makes an appointment after work.

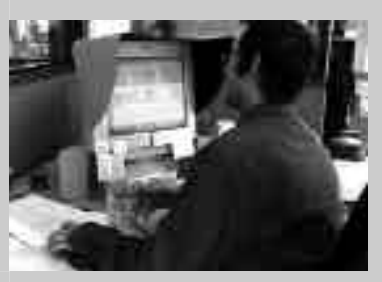

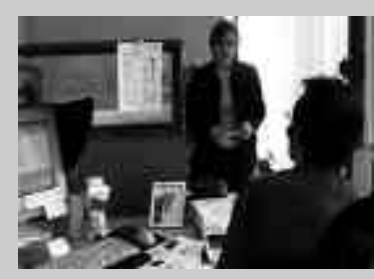

b) (Colleague) While waiting for the customer to answer Rickard questions his colleague.

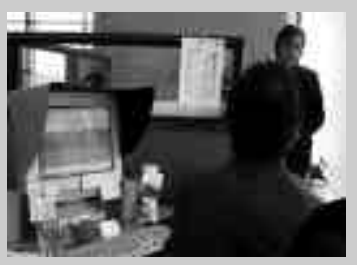

d) (Colleague) Rickard is waiting to be put through and uses the pause to finish his conversation with his colleague.

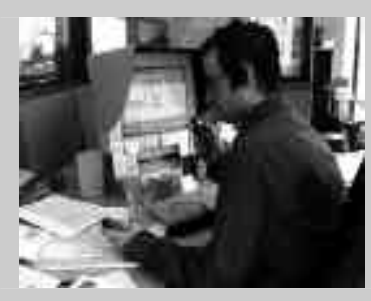

f) (Friend) Rickard fetches a number from his private cellular phone and calls a friend.

h) (Sales agent) Rickard confirms an appointment with the customer.

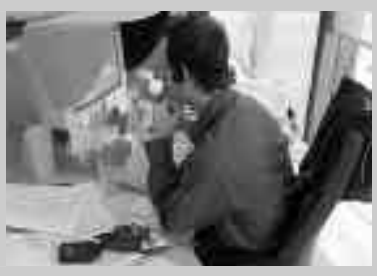

j) (sales agent) Rickard turns back to work on his PC.

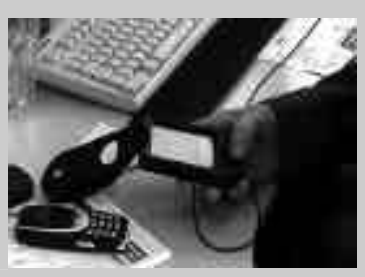

Figure 2. Handling multiple devices and identities.

different devices clearly indicates that this is part of Rickard's everyday working life. Handling multiple devices and identities in communication seems to come natural to Rickard. Early research in context awareness has focused on geographical position and identity as the major contextual factors 
[1]. In this example Rickard is not mobile, but the fact that he uses mobile technology enables him to be present in multiple social spaces and, as Gant \& Kiesler suggest [8], the boundary between work and other activities is then blurred. Abowd \& Mynatt suggest that identity should be expanded to include other people in the environment as 'we tailor our activities and recall events from the past based on the presence of other people' [1, p.9]. Arguably, being omni-present in multiple social spaces suggests an even more complex picture where different identities come into play. Rickard's communicative behaviour and priorities is dependent on what role he is currently engaged in. Each social role brings with it a social context influencing behaviour in the specific situation. In conclusion, the dynamics displayed in Rickard's context, while maintaining the same geographical position, suggests that our omni-presence in multiple social contexts - our 'social mobility' - is an important part of understanding contextual factors of IT use.

\section{The Tap On the Shoulder - Taking Multiple Social Roles}

The second example, also captured in our field data, shows Ronny, a head-hunter recruiting professionals. In this situaion Ronny is having trouble reaching one of his sons Jakob. Ronny is a frequent user of mobile IT since his professional role requires him to be available at all times, and he rarely switches off his mobile phone. His wife allows him to take business calls at home but does not fully approve. While commuting by train Ronny is calling home to see if his son Jakob is okay. Jacob is old enough to get home from school on his own, but Ronny always calls on his way home to check on him. This time there is no answer. Getting off the train Ronny tries again, but there is still no one home. He picks up his second son at the day-care centre. On arriving home he phones the activity centre where Jakob goes after school to inquire if he is there. He is not. Ronny starts walking around the neighbourhood searching for Jakob. He finally finds Jakob playing with some friends. This situation describes one of eight short ethnographic video stories used in workshop 1. It introduces Ronny as a user and his scenario as design material when inquiring into the needs of his situation. This scenario opens a possible concept called the 'personal messaging device'. This handheld device offers asynchronous messaging (e.g. SMS or email). This would then allow users to read and write digital messages, anytime and anywhere via text or voice, the basic functionality being to allow people to send short messages and to receive quick responses. This would therefore synchronize activities between people who aren't in the same place at the same time. After the workshop, together with Ronny, the device was further refined and validated. As part of the preparations for workshop 2 Ronny and his son Jakob role played a video recorded scenario in their everyday contexts illustrating the use of the 'personal messaging device'. Here Jakob uses the device to send a quick request to Ronny asking if he can go to a friend's house and play after school (see figure 3). Obviously, Ronny constantly occupies (at least) the two social roles of being a business professional

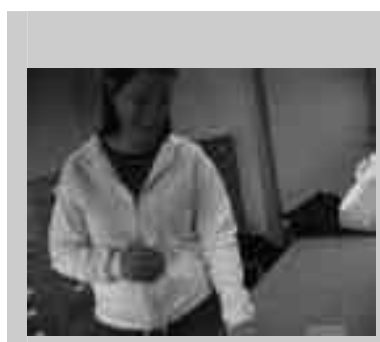

a) Ronny's son Jakob is at the activity center after school. He wants to go to Viktor's home to play. He asks Cornelia for permission to do this.

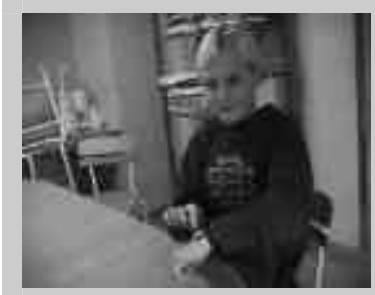

c) Jakob sends a spoken request to Ronny using his personal messaging device.

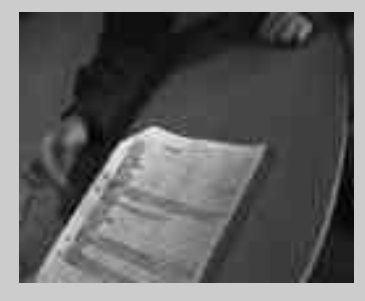

b) Cornelia checks the schedule for Jakob, he is being picked up at 15.00 .

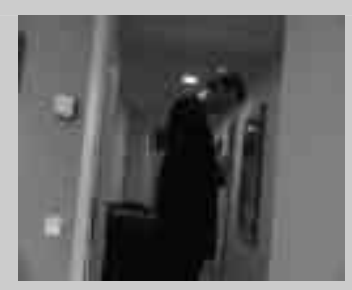

d) Ronny receives the message from Jakob as text on his personal messaging device. He answers by pressing the green 'OK-button'.
Figure 3. Jakob 'taps dad on the shoulder'.

and father. To Ronny, staying in touch with his loved ones is of high priority at all times, although it should not conflict with his role as a business professional. The information to be communicated within the family when they are not present in the same context is often short messaging, e.g. confirming that Jakob is allowed to go to a friend's house after school. At best confirmation should be quick. For Ronny, being in a work setting, the request from Jakob is an example of how one can shift seamlessly between work activities and personal activity as referred to by Sherry \& Salvador [18]. According to Ronny, his personal life is compromised when in an important business meeting. The existing technology of email or SMS would require too much attention as well as compromising his business etiquette. This is one scenario Ronny cannot manage. However, a 'personal messaging device' would enable him at a glance to fulfil his parent role by simply answering 'yes' or 'no' to Jakob's request without compromising his business etiquette.

The 'personal messaging device' has similarities with the 'Quiet Call' concept developed by Nelson et al. [13]. They developed a technology allowing users to respond to phone calls without talking aloud. Nelson et al. have primarily focused on how to have private conversations while in public places and suggest the concept 'Quiet Calls', which allows the caller and callee to use separate modes of communication. The participants can use a quiet mode, whereby it is possible to listen to the caller and answer through three buttons with pre-set configurations of pre-recorded answers. While 'Quiet Calls' allow for wide variety, the purpose of the 'personal messaging device' is intended only to support relations only 
between a limited number of people, often the family. At the second workshop, the use qualities of the enacted scenarios identified together with Ronny include: 'Semi-asynchronous communication'; 'Feeling secure: where is Jacob?'; 'Invisible bonding'; 'Supporting family planning activities'; 'Allowing for a rapid response'. From Jakob's perspective, the primary use quality is to have 'easy access to his parents'. He wants to be able to 'tap dad on the shoulder' at any given time. Using the 'personal messaging device' Ronny can respond discretely to a short message from his children. For Ronny this could be handled either by a separate device or as a service implemented in his mobile phone, whereas Jakob being too young for using a mobile phone it would require him to use a simpler device for rapid asynchronous communication. To summarize, the 'personal messaging device' was based on rapid ethnography where we experienced Ronny worrying about his son's whereabouts while on his way home from work. This scenario and concept highlights some of the challenges in trying to cope with multiple social roles and contexts. An important quality of the device is the security that both Jakob and Ronny have when needing to communicate with one another - i.e. a 'tap on the shoulder' works both ways.

\section{Sharing Information - Compiling And Displaying Informa- tion On the Move}

In the following three connected scenarios, Ronny and his colleagues demonstrate how they would like to use several mobile devices to capture, compile and share information about a job vacancy (see figure 4). The first scenario takes place at the client's office in a nearby town, where Ronny's two co-consultants meet with a client (here played by Ronny) to establish their recruitment needs for a new position. In the second scenario, still being at the client's office, the two coconsultants compile information directly after the meeting, send it to a shared workspace as well as alerting Ronny to the updated information. Finally, the third scenario shows Ronny accidentally meeting one of his listed candidates (here played by Ronny's co-consultant) at a café and is able to present her with information on the vacancy. The video scenarios were part of the session about exploring use experiences in the second workshop. To Ronny the most important use quality in these scenarios was that the mobile technology facilitates a direct mediation of information about a job position from a client to a possible candidate. He valued the efficiency of handling and sharing digital material. He regarded the on-thespot video recording of the client presenting the job position of particular value. To the best of his knowledge this had not been done by anyone before. The video clip would then allow Ronny to observe potential candidates while they are viewing the job position on offer. According to Ronny, watching the candidate's immediate response to the recorded presentation gives valuable information about the candidate's level of interest. Not least, the facilitation of an 'asynchronous meeting', though supporting only one-way communication, saves valuable time in the recruitment process, according to Ronny.

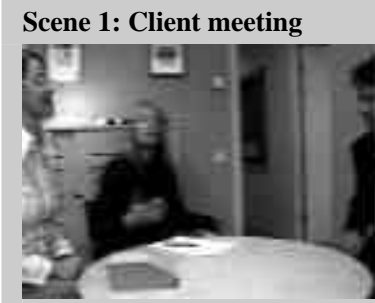

a) Ronny's two co-consultants meet with a client who describes his recruiting requirements.

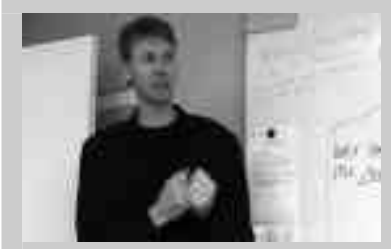

c) The recording is made using the 'video device'.

Scene 2: After the client meeting

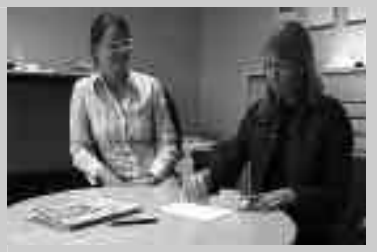

a) Emma scans both her notes and an organization chart from the client using the 'handheld scanner'.

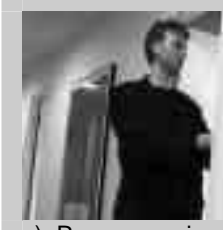

c) Ronny receives a message about the updated files on his 'personal messaging device'.

Scene 3: Unanticipated client meeting

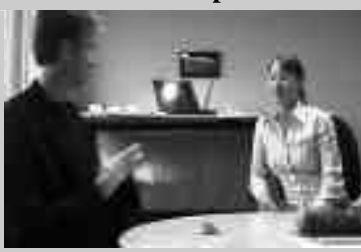

a) Ronny is having an unanticipated meeting with a candidate for the recruiting assignment. He wants to display the video recorded presentation of the position on offer.

Figure 4. Sharing information.

These scenarios serve as a good example of how user's role playing in scenarios can identify needs that can be supported by a set of devices with simple functionality. These devices b) By the end of the meeting the client is offered the possibility to record a brief presentation of both company and the position on offer.

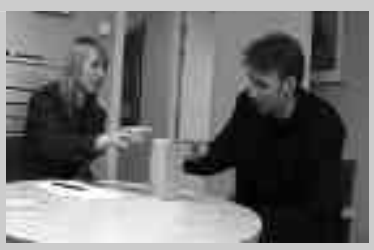

d) The client requests Louise to do some quick editing on the spot using the 'video device'.

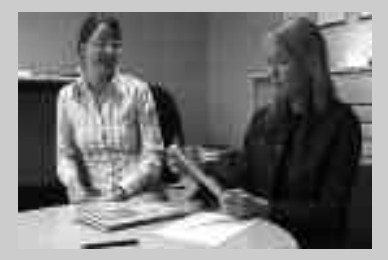

b) This data is sent to a shared workspace directly from the 'handheld scanner'.

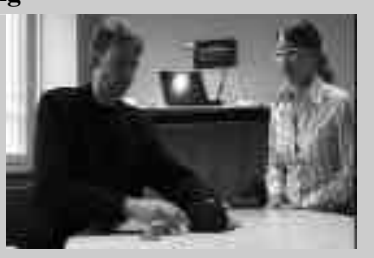

b) Ronny retrieves the video clip from the shared work space using his 'personal messaging device'. The video clip can then be viewed on his palmtop.

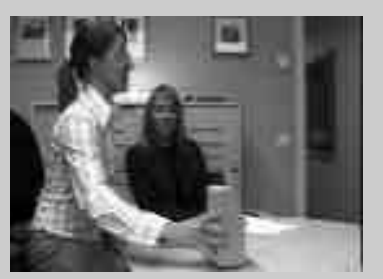


may be off-the-shelf products or products for release in the near future. The 'video device', 'handheld scanner', 'personal messaging device', palmtop and shared workspace with wireless access are configured to act in concert to provide communication between users driven by the particular needs of a specific context - the mediation of information between a client and a job candidate. Sherry and Salvador [18] identify the creation of information in digital form as one of the most under-supported activities for mobile professionals. In their study users lacked support for simple tasks like taking notes or scrawling brief messages. The PDA was regarded as too difficult to use for data entry beyond simple contact information and the laptop too slow to start and cumbersome to use for these tasks. This is in line with the feed-back from the users in the COMIT project. In general they found today's devices too complicated to use in concert for communication.

\section{Configuring a 'Portable Print Shop'}

Similar to the previous scenario, the following shows how a set of devices with basic functionalities are configured for a particular context (see figure 5). As a fashion designer, Helle renews her collection every year. In an enacted scenario Helle demonstrates how she uses three concepts - the 'image device', 'image editing tablet', and 'portable printer' - to produce a catalogue for a retailer, showing a selected set of garments from her collection with annotations. The resulting personalized catalogue contains pictures and information about the garments the retailer has showed interest in, together with prices (which may be specific for the retailer) and information about possible variations, colours, etc. The use qualities identified in the second workshop for the above scenario pointed out the added value to the customer of having a 'personalized catalogue'. Helle operates in a competitive market and in order to promote her products she regularly visits companies to present her current collection. However, fashion designers in general promoting small collections cannot afford to produce complete catalogues.

For Helle the chances of selling products increase if she can leave documentation of her collection with the customer for future reference. The ability to annotate the images with agreed prices and other information, and thereby personalizing the catalogue as a response to direct questions from the retailer, improves her customer relations and gives her a temporary competitive edge. On a practical level, the catalogue also serves as future reference to what she has offered to each retailer. This example shows how mobile technology can be powerful in supporting the contextualization of information content. More important, Helle configures a set of devices, each with simple functionality, to perform functions based on the needs of a particular context. The combination of the 'image device' and the 'editing tablet' originated from discussing how her digital camera could be used in her atelier. In this case, annotated photos of garments in production could be sent to customers for perusal. However, in this scenario Helle expands this idea by bringing together three devices, all of which have simple functionality that is available in

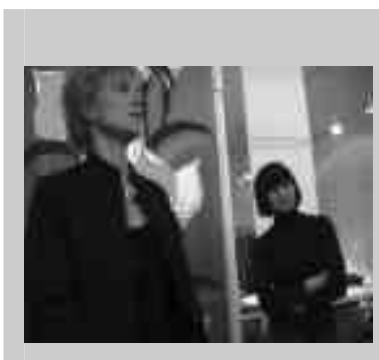

a) Helle shows her new collection to Elisabeth, a company represen-tative.

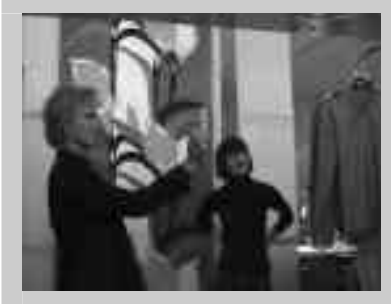

c) Helle takes pictures using her 'image device' of the garments Elisabeth is interested in.

e) Finally, Helle sends the set of annotated pictures from her 'image editing tablet' to her 'portable printer', producing a personalized catalogue.

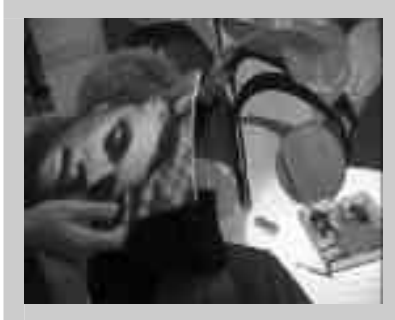

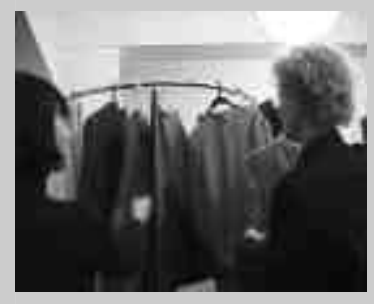

b) Together they browse through the collection and Helle comments the different garments and answers questions from Elisabeth.

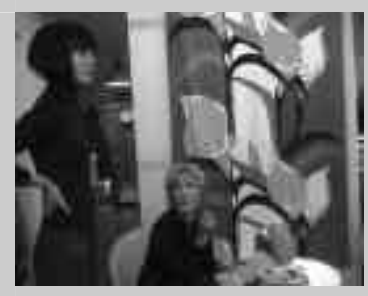

d) Helle annotates the pictures with comments regarding prices, colours, etc., using her 'image editing tablet'.

\section{Figure 5. Displaying the collection.}

off-the-shelf products. These can act in concert to provide the function of a 'portable print shop'. The detailed features of each of the separate devices are not critical. The 'image device' (i.e. digital camera) and printer only needs resolution high enough to produce print with reasonable quality in A5format. The function requirements of the 'editing tablet' are also simplistic. It should provide possibilities for simple annotations directly in the images. The qualities of use are delivered through the configuration of the three devices as a 'portable print shop' based on the needs of the particular context - the business meeting where Helle presents her collection to a retailer. The mobile 'portable printshop' is a further example of how digital information is created in a mobile setting, based on the needs of a particular situation. This creates added value by way of services, for both parties (Helle as well as her retailers). 


\section{CONCLUSION}

Increased connectivity in mobile technologies, coupled with increased dynamics in user needs, provide new challenges for the design of mobile technology. Our aim with the COMITproject has been to explore new avenues of inquiry into mobile user's needs in order to inform the early stages of the design process, with particular emphasis on contextual factors and connectivity. We have combined rapid ethnography with participatory design in an event-driven process where users, designers and researchers have collaborated in developing ideas for mobile technology on a conceptual level. The overall experience gained from the project is that we were able to generate a useful knowledge base that caters for the specific design process, as well as indicators for more general issues on mobility, using relatively little resources. Our short field studies provided a first base for generating concepts and scenarios that were well grounded in the user's everyday worlds. Bringing the concepts developed back to the user's context at an early stage without detailing the interaction was an important step in empowering the users. By letting the users themselves create mock-ups with simple materials that were used as props in role playing scenarios on location, proposed concepts were refined and new concepts were rapidly identified and developed with a firm grounding in the user context. For instance, Helle's 'portable print shop' for personalizing a collection catalogue to a retailer was a concept developed during scenario enactment around the image device and image editing tablet. Although our aim was not primarily to search for potential products, the participating companies judged some of the concepts developed as holding valuable information for future product development. Another outcome of the project was that one of the industrial partners, Sony Ericsson Mobile Communications, has engaged in a project based on the COMIT design approach.

Regarding general issues on mobility indicated in our collaborative inquiry, we find the consequences of being omnipresent in multiple social contexts important in designing mobile technology. As designers we should be sensitive to the different social roles of the user in different contexts, as well as how these roles may imply different user needs. In the first two examples above we have tried to identify some issues involved in handling multiplicity in identities, social contexts and devices. This is an area in need of further exploration. Mobile devices has opened new possibilities of information technology use in space and time, and consequently the expectations on peoples' availability for communication has increased. However, the most important difference is that increased availability means that we co-exist in a multitude of social contexts. Even if location is static, it is the use of mobile technology that opens for our omni-presence in multiple social contexts. This is not to say that the geographical location of the user is irrelevant. That would lead back to the slightly outdated marketing view of the nomadic user as context independent, free to do business anywhere anytime. It is rather about the users' ability to adapt to the needs of the current situation. Physical location fixates certain contextual factors - it might be a noisy environment, or an area where only low bandwidth communication is available. A greater challenge is to support the user in handling multiple social roles, given the contextual factors of the social situation. Ronny wants to be able to handle communication with his family at any given time. This is characterized by short messages, quick responses and a certain discretion and intimacy while in ordinary business communication. The most important use quality for Ronny revolves around emotional awareness of his family's well-being and organization of daily arrangements. The scenario from Rickard's daily work also indicates a need for being available to his closest social network in parallel with being a sales agent. The 'personal messaging device' gives a first direction for possible solutions. However, as already mentioned the concepts developed in this project are not to be seen as potential products, but rather as placeholders for artefacts mirroring relevant aspects of mobile technology and its potential/shortcomings. The main issue requiring further research is how to support fluency in handling multiple social contexts that allow the users to operate in their different roles in daily life while still responding to the dynamic contextual factors of particular situations.

A further observation is that, in the future scenarios created together with the users, we found that the use qualities often emerged from the different devices acting in concert to provide a function, rather than from the basic functionalities in each device. On a conceptual level this implies to us as designers that, rather than focusing entirely on the separate devices, their functions and prospective use qualities, we should direct our attention to what the relevant configurations of a set of devices can deliver to the user. The trend towards information appliances [15] suggest that devices should be task focused while still being able to communicate with other devices. Sherry \& Salvador [18] recognize another trend where increased connectivity via Bluetooth ${ }^{\mathrm{TM}}$ and other technologies rather points towards a disarticulation of the elements of computing. Storage, display, software for main functions and other elements are separated in different devices implying a more 'architectural' approach to providing services to users. In line with these ideas the last two examples serve to illustrate that use qualities do not necessarily emerge on a device level. Rather, in these scenarios the most important use qualities emerge on the level of a configured set of devices. Arguably, it is the particular device configuration as a response to the needs of a use situation that produces relevant use qualities, suggesting a shift in the design agenda regarding what to design in mobile technologies. This further implies that the designated functions of a device may be defined on a level more loosely connected to specific user activities. The cell phone being re-configured as a remote control referred to in the introduction, may be reframed to be portable keypad supporting wireless communication with other devices. From this perspective, technology is deliberately open to configuration to further enable the user to manipulate freely the adaption of various devices in any given situation. This implies 
that the user could be in control of configuring, manipulating and adapting mobile devices to their personal needs.

In conclusion, our exploration of contextual issues in mobile computing has indicated several avenues in need of further research. Regarding multiple social contexts, we need to develop a deeper understanding in how to support users in coping with different social roles as well as the different needs associated with them. Regarding multiple devices and connectivity, our explorations have suggested that important use qualities may emerge from sets of devices configured by the user, rather than single devices. We need to further pursue possiblities in letting users configure devices for particular situations. Finally, a combination of field studies and collaborative design has been a fruitful approach for our inquiry into contextualizing mobile IT.

\section{ACKNOWLEDGEMENTS}

We thank Sony Ericsson Mobile Communications AB for their participation and financial support in the project, and Anoto AB, Decuma AB and Telia Research AB for their participation. We also thank our three prospective users, Helle, Ronny and Rickard for their cooperation.

\section{REFERENCES}

1. Abowd, G. D., and Mynatt, E. D. Charting past, present and future research in ubiquitous computing. ACM

Trans. Computer-Human Interaction, 7, 1 (Mar. 2000), pp. 29-58.

2. Binder, T: Setting the Stage for Improvised Video Scenarios. CHI99 Conference. 1999.

3. Brandt, E., and Grunnet, C: Evoking the future: drama and props in user centered design. In Cherkasky, T., Greenbaum, J., Mambrey, P. (Editors), Proceedings of Participatory Design Conference, New York, CPSR, 2000. pp. 11-20.

4. Brandt, E. Event driven product development - collaboration and learning. PhD dissertation, Dept. of Manufacturing Engineering and Management, Technical University of Denmark. 2001.

5. Brandt, E and Messeter, J. Facilitating Collaboration through Design Games. To be presented at the Participatory Design Conference. Toronto, 2004.

6. Buur J., Binder T. and Brandt E. Taking video beyond 'Hard Data 'in user centred design. In Proceedings of Participatory Design Conference (PDC 00), New York 2000.

7. Dix, A., Rodden, T., Davis, N., Trevor, J. Friday, A., and Palfreyman, K. Exploiting space and location as a design framework for interactive mobile systems. ACM Trans. Computer-Human Interaction, 7, 3 (Sep. 2000), pp. 285-321.

8. Gant, D. and Kiesler, S. Blurring the Boundaries: Cell Phones, Mobility, and the Line between Work and Personal Life. In B. Brown, N. Green and R. Harper (eds.): Wireless World: Social and Interactional As- pects of the Mobile Age. London: Springer Verlag, pp. 131-141, 2002.

9. Gaver, B., Dunne, T. and Pacenti, E. Cultural Probes. ACM Interactions, January-February, 1999, pp. 21-29.

10. Harper R. (2001): The Mobile Interface: Old Technologies and New Arguments. In B. Brown, N. Green and R. Harper (eds.): Wireless World: Social and Interactional Aspects of the Mobile Age. Godalming and Hiedleburg: Springer Verlag, pp. 36-49.

11. Ishii, H. and Ullmer, B (1997). Tangible Bits: Towards Seamless Interfaces between People, Bits and Atoms. Proceedings of the SIGCHI conference on Human factors in computing systems (CHI'97), pp. 234-241.

12. Johansson. M., Fröst, P., Brandt, E., Binder, T. and Messeter, J. Partner Engaged Design - New challenges for workplace design, in Proceedings of Participatory Design Conference (PDC) 2002, Malmö Sweden.

13. Nelson, L, Bly, S. and Sokoler, T. Quiet Calls: Talking Silently on Mobile Phones. CHI 2001.

14. Nilsson, J., Sokoler, T., Binder, T., and Wetcke, N. (2000). Beyond the control room: Mobile devices for spatially distributed interaction on industrial process plants. Proceedings, Handheld and Ubiquitous Computing (HUC) 2000.

15. Norman, D. (1998) The invisible Computer - Why good products can fail, the personal computer is so complex, and information appliances are the solution. MIT press, Cambridge Massachusetts USA, 1998 p.219-233.

16. Rowson, J. The Social Media Project at Hewlett Packard Laboratories. http://netseminar.stanford.edu/sessions/2001-1101.html.

17. Sawhney, N. \& Schmandt, C: Nomadic Radio: Scaleable and Contextual Notification for Wearable Audio Messaging. In Proceedings of the SIGCHI conference on Human factors in computing systems (CHI '99), p96-103, Pittsburg, U.S., May 15-20, 1999.

18. Sherry, J. \& Salvador, T. Running and Grimacing: The Struggle for Balance in Mobile Work. In B. Brown, N. Green and R. Harper (eds.): Wireless World: Social and Interactional Aspects of the Mobile Age. London: Springer Verlag, pp. 108-120, 2002.

19. Taylor, A. S. \& Harper, R. The Gift of the Gab?: A Design Oriented Sociology of Young People's Use of Mobiles. Computer Supported Cooperative Work, 12:267-296, 2003.

20. Weiser, M. The Computer for the 21st Century. Scientific American, 265 (3), 1991, pp. 94-104.

21. Wellner, P., Mackay, W., and Gold, R. (1993) Computer Augmented Environments: Back to the Real World. Commun. ACM, Vol. 36, No. 7, July 1999. 